\title{
The effect of acid drinking water on rumen protozoa in the blesbok (Damaliscus dorcas phillipsi)
}

\author{
D. G. BOOYSE ${ }^{1}$, B. A. DEHORITY ${ }^{2 *}$, J. G. MYBURGH ${ }^{3}$ \\ ${ }^{1}$ Department of Anatomy and Physiology, University of Pretoria, Private Bag X04, Onderstepoort 0110 \\ South Africa. \\ ${ }^{2}$ Department of Animal Sciences, Ohio Agricultural Research and Development Center, The Ohio State \\ University, Wooster, $\mathrm{OH} 44691$ \\ ${ }^{3}$ Department of Paraclinical Sciences, Faculty of Veterinary Science, University of \\ Pretoria, Private Bag X04, Onderstepoort, 0110 South Africa.
}

\begin{abstract}
Rumen contents were collected from ten adult female blesbok, five from a mine area with only acid drinking water available and five from a control group consuming normal, non-polluted drinking water. The mean concentration of total protozoa in the normal water group was almost double that in the acid drinking water group, $24.9 \mathrm{x}$ $10^{3}$ versus $14.7 \times 10^{3}$. Percent of Entodinium was higher and Diplodinium lower in those animals drinking the acid water. The number of different protozoa species present in animals from both locations was fairly similar. Diplodinium bubalidis, Ostracodinium gracile and Diplodinium consors were present in the highest percentage in the normal water group, $18.8,18.4$ and $17.7 \%$, respectively. The same three species, plus Entodinium dubardi, were also highest in the acid water group, O. gracile, $21.3 \%$; D. consors, $12.6 \%$; E. dubardi, $11.4 \%$ and D. bubalidis, $10.3 \%$. Seventeen species of protozoa found in this study were a new host record for the blesbok, bringing the total number of species reported from the blesbok to 29 .
\end{abstract}

Keywords: Acid drinking water, Blesbok, Damaliscus dorcas phillipsi, Rumen, Protozoa.

\footnotetext{
${ }^{*}$ Author for correspondence. E-mail: dehority.1@osu.edu
} 


\section{Introduction}

Because of reported blesbok deaths in the area of an abandoned gold and uranium mine, Nothling et al. (2014), conducted a study in which they measured lead isotope ratios in bone ash of animals consuming acid water draining from the mine. In addition, these same measurements were taken on animals from a different area consuming non-contaminated drinking water. They found that the blesbok drinking the acidic water had accumulated higher concentrations of uranium in their tibia bones, presumably as a result of this element leaching from uraniferous rocks. The present study was undertaken to determine whether the acid mine water may have also contributed to changes in the rumen protozoa and affected animal health.

\section{Materials and methods \\ Collection sites}

Five female blesbok were harvested from the Krugersdorp Game Reserve (KGR) (26음 05 ' 11" S and $27^{\circ}$ ' $42^{\prime} 45^{\prime \prime} \mathrm{E}$ ) in the Gauteng Province of South Africa. These animals only had access to acidic drinking water. The control group of five female blesbok, drinking from a normal water supply, were harvested from the Rhino and Lion Nature Reserve (RLNR) which is located approximately $15 \mathrm{~km}$ north-east of KGR.

\section{Drinking water}

A sample of the water being consumed by the blesbok was collected at each site and returned to the lab for measurement of $\mathrm{pH}$. Water from the mine area had a $\mathrm{pH}$ of 3 while the normal drinking water had a $\mathrm{pH}$ of 7 .

\section{Sample collection}

Handfuls of rumen digesta were squeezed in the fist with the thumb pointing downwards so that liquid could run down into a plastic container. This was repeated until a $40 \mathrm{ml}$ sample was obtained. This volume was then transferred to a $100 \mathrm{ml}$ bottle and $40 \mathrm{ml}$ of $40 \%$ formalin was added to preserve the sample.

\section{Counting protozoa}

Because of the high concentration of protozoa, a $1 \mathrm{ml}$ sub sample of the fixed rumen fluid sample was diluted to $5.0 \mathrm{ml}$ by adding $4.0 \mathrm{ml}$ of water. Two drops of Brilliant Green Stain were added and the sample was allowed to stand overnight. Using a finnpipet, 
$0.025 \mathrm{ml}$ of the stained sample was placed on a glass microscope slide, covered with a glass cover slip and the protozoa were counted. Each sample was counted in triplicate. Results of the $0.025 \mathrm{ml}$ count were multiplied by 400 to give the concentration of protozoa per $\mathrm{ml}$ of rumen fluid.

\section{Results and Discussion}

Concentration and generic distribution of rumen protozoa in the blesbok drinking normal or acid water are shown in Table 1. The overall mean value for protozoa concentration $/ \mathrm{ml}$ was almost double for the animals drinking normal water, i.e., $24.9 \mathrm{x}$ $10^{3}$ compared to $14.7 \times 10^{3}$. The range of values in the normal drinking water group, 8.2 $-39.4 \times 10^{3} / \mathrm{ml}$, was much greater than that in the acid drinking water group, 12.4-19.2 $\times 10^{3} / \mathrm{ml}$. This is reflected in the higher standard deviation in the control group, \pm 12.6 versus that in the acid water group, \pm 2.7 . A number of studies have shown that lowering of rumen $\mathrm{pH}$ by feeding high concentrate diets markedly lowers protozoa concentrations (Latham et al.,1971; Abe et al., 1973; Mackie et al.,1978; Towne et al., 1988; Franzolin and Dehority, 1996). Dehority (2005), working in vitro with monocultures of Entodinium caudatum, Entodinium exiguum, Epidinium caudatum and Ophryoscolex purkynjei, observed that numbers of all four species decreased markedly below $\mathrm{pH} 5.8$ and the protozoa were no longer viable at a $\mathrm{pH}$ of 5.3. Unfortunately, in the present study $\mathrm{pH}$ of the rumen contents was not measured. However, drinking water with a $\mathrm{pH}$ of 3.0 should have markedly reduced rumen $\mathrm{pH}$.

The blesbok primarily consumes grasses, which would account for the low percentage of Entodinium species, 5.0 to $17.1 \%$ in the control animals. In a previous study on protozoa in wild African ruminants, those animal species which consumed only grasses and roughages, the hartebeest and wildebeest, had percentages of Entodinium ranging from 6 to 16\% (Dehority and Odenyo, 2003). As in the present data, the majority of protozoa were Diplodinium and Ostracodinium species. In contrast, the concentrate and intermediate feeders, which presumably had a lower rumen $\mathrm{pH}$, had Entodinium percentages ranging from 41 to $100 \%$. This is closer to the range in the acid water group, 10 to $61 \%$. 
Table 1. Concentration and generic distribution of rumen protozoa in blesbok drinking normal or acid water.

\begin{tabular}{|c|c|c|c|c|c|c|c|c|c|c|c|c|}
\hline & \multicolumn{6}{|c|}{ Normal drinking water } & \multicolumn{6}{|c|}{ Acid mine drinking water } \\
\hline & 1 & 2 & 3 & 4 & 5 & Mean \pm SD & 1 & 2 & 3 & 4 & 5 & Mean \pm SD \\
\hline Total protozoa $\left(\times 10^{3} / \mathrm{ml}\right)$ & 8.2 & 18.0 & 23.6 & 39.4 & 35.2 & $24.9 \pm 12.7$ & 12.9 & 14.4 & 19.2 & 12.4 & 14.4 & $14.7 \pm 2.7$ \\
\hline \multicolumn{13}{|l|}{ Genus $(\%)$} \\
\hline Entodinium & 17.1 & 14.9 & 16.9 & 5.1 & 14.8 & $13.8 \pm 5.0$ & 19.4 & 30.6 & 10.4 & 61.3 & 27.8 & $29.9 \pm 19.2$ \\
\hline Diplodinium & 68.3 & 36.2 & 27.1 & 40.6 & 21.6 & $38.8 \pm 18.1$ & 24.8 & 22.2 & 29.2 & 22.6 & 41.7 & $28.1 \pm 8.1$ \\
\hline Eudiplodinium & 0 & 0 & 15.3 & 12.2 & 19.9 & $9.5 \pm 9.1$ & 0 & 2.8 & 4.2 & 0 & 2.8 & $2.0 \pm 19$ \\
\hline Ostracodinium & 4.9 & 46.8 & 37.3 & 37.6 & 38.6 & $33.0 \pm 16.2$ & 31.0 & 33.3 & 56.3 & 16.1 & 27.8 & $32.9 \pm 14.7$ \\
\hline Epidinium & 0 & 0 & 0 & 0 & 0 & 0 & 0 & 2.8 & 0 & 0 & 0 & $0.6 \pm 1.1$ \\
\hline Opisthotrichum & 9.8 & 2.1 & 3.4 & 4.1 & 4.5 & $4.8 \pm 3.0$ & 24.8 & 8.3 & 0 & 0 & 0 & $6.6 \pm 10.8$ \\
\hline Dasytricha & 0 & 0 & 0 & 0.5 & 0 & $0.1 \pm 0.2$ & 0 & 0 & 0 & 0 & 0 & 0 \\
\hline
\end{tabular}


In general, the percentage Entodinium was increased and Diplodinium and Eudiplodinium decreased in the acid drinking water group. The percentage of Ostracodinium was similar between the two groups. The increase in Entodinium at lower rumen $\mathrm{pH}$ values would agree with earlier in vivo observations (Vance et al., 1972; Lyle et al., 1981; Towne et al., 1988; Franzolin and Dehority, 1996). However, the in vitro studies by Dehority (2005) did not suggest any lower $\mathrm{pH}$ tolerance for Entodinium species.

Table 2 presents the species distribution of protozoa in the two groups. For those animals drinking normal water, a total of 19 species were observed among the five animals. A total of 13 species occurred in one animal followed by 12,10, 9 and 5 in the remaining blesbok. Over $50 \%$ of the total population was comprised of three species, Diplodinium bubalidis (18.8\%), Ostracodinium gracile (18.4\%) and Diplodinium consors (17.7\%).

In the group drinking acid water, 22 species were present. One animal contained 14 species, one animal had 10 species, two had 9 and the fifth animal contained 8 species. The same three species as in the normal group made up $44 \%$ of the fauna: Ostracodinium gracile (21.3\%), Diplodinium consors (12.6\%) and Diplodinium bubalidis (10.3\%). Epidinium dubardi comprised $11.4 \%$ compared to only $6.2 \%$ in the normal drinking water group. Only 14 species were common to both groups.

The protozoa faunas of 26 young blesbok were studied by van Hoven (1978). The animals were harvested from a farm in the Western Transvaal province of South Africa. The animals ranged in age from 3 to 21 months with a mean protozoa concentration of $29 \times 10^{4} / \mathrm{ml}$. This concentration is almost 10 -fold higher than found in the normal group in the present study. However, no information is available on the diet of the animals in either study. A total of 12 species were identified in the 26 animals, two of which were not found in this study, Ostracodinium garstangi and Entodinium fyferi. Across all animals, the average percentages of Ostracodinium gracile, Diplodinium consors and Diplodinium bubalidis were 4.9, 12.8 and 15.5\%, respectively, for a total of $33 \%$ of the total species. This is somewhat lower than the total for these three species found in the present study; however, these were young animals compared to adults. Only two species of Entodinium were found, Entodinium fyferi and Entodinium parvum. 
Table 2. Percent species distribution of rumen protozoa in blesbok drinking from a normal or acid drinking water supply.

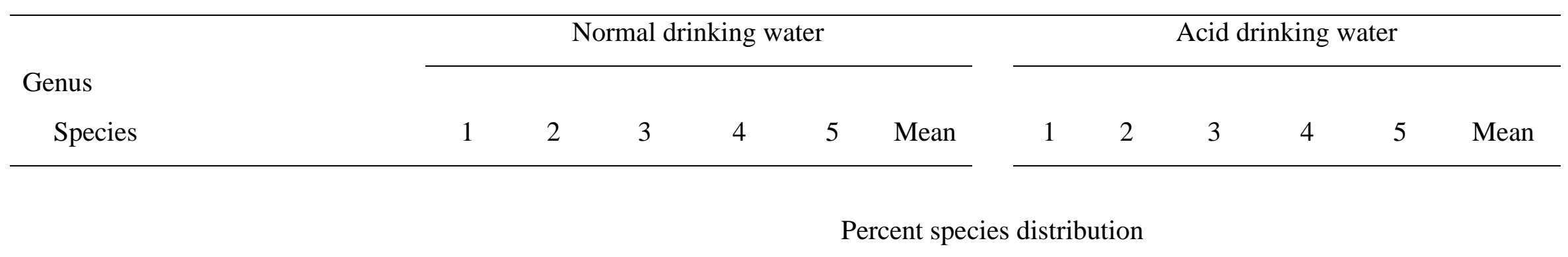

\section{Dasytricha}

ruminantium Shuberg, 1888

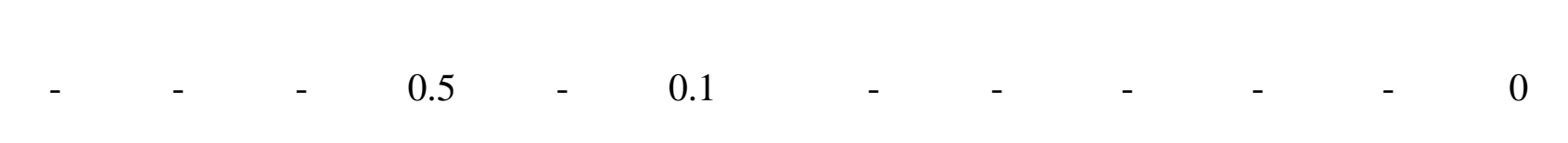

\section{Entodinium}

acutonucleatum $\mathrm{K} \& \mathrm{M}^{\mathrm{a}}$, 1930

bimastus Dogiel, 1927

dubardi Buisson, 1923

exiguum Dogiel, 1925

furca Cunha, 1914

nanellum Dogiel, 1922

parvum Buisson, $1923^{\mathrm{b}}$

simplex Dogiel, 1925

taurinus B \& D ${ }^{\mathrm{c}}, 2012$

Species $^{\mathrm{d}}$

$\begin{array}{cccccc}- & - & 1.7 & - & - & 0.3 \\ - & - & - & - & - & 0 \\ - & 8.5 & 10.2 & 3.0 & 9.1 & 6.2 \\ - & - & - & 2.0 & 3.4 & 1.1 \\ - & - & - & - & - & 0 \\ - & - & - & - & - & 0 \\ - & 2.1 & - & - & - & 0.4 \\ - & 2.1 & - & - & - & 0.4 \\ 4.9 & - & 3.4 & - & - & 1.7 \\ 12.2 & 2.1 & 1.7 & - & 2.3 & 3.7\end{array}$

$\begin{array}{cccccc}- & - & - & 6.5 & - & 1.3 \\ 3.1 & - & 4.2 & 19.4 & - & 5.3 \\ 12.4 & 13.9 & 2.1 & 6.5 & 22.2 & 11.4 \\ 0.8 & 8.3 & - & - & - & 1.8 \\ - & 2.8 & - & - & - & 0.6 \\ - & - & - & - & 2.8 & 0.6 \\ - & 5.6 & - & - & - & 1.1 \\ - & - & - & - & - & 0 \\ - & - & - & 29.0 & 2.8 & 6.4 \\ 3.1 & - & 4.2 & - & - & 1.5\end{array}$




\section{Diplodinium}

aspinosum Ito et al. ${ }^{\mathrm{e}}, 1997$

bubalidis Dogiel, 1925

consors Dogiel, 1925

costatum Dogiel, 1925

dogieli Dogiel, 1925

minor Dogiel, 1925

rangiferi Dogiel, 1925

\section{Eudiplodinium}

giganteum Dogiel, 1925

impalae Dogiel, 1925

insigne Dogiel, 1925

neglectum Dogiel, 1925

\section{Ostracodinium}

gladiator Dogiel, 1925 gracile Dogiel, 1925

nanum Dogiel, 1925

tenue Dogiel, 1925

$\begin{array}{cccccc}- & - & - & - & - & 0 \\ 43.9 & 12.8 & 16.9 & 19.3 & 1.0 & 18.8 \\ 24.4 & 23.4 & 8.5 & 12.2 & 20.0 & 17.7 \\ - & - & - & - & - & 0 \\ - & - & 1.7 & 9.1 & - & 2.2 \\ - & - & - & - & - & 0 \\ - & - & - & - & - & 0\end{array}$

3.

3.1

6.2

- 2

$-\quad 2.8$

- $\quad 5.6$

20.8

8.3

$\begin{array}{cccc}- & - & - & 1.2 \\ - & - & 2.8 & 1.1 \\ - & - & - & 0.6 \\ - & - & 2.8 & 1.7\end{array}$

$\begin{array}{cccccc}- & - & 5.1 & 3.0 & - & 1.6 \\ - & - & 10.2 & 8.1 & 9.1 & 5.5 \\ - & - & - & 1.0 & 1.0 & 0.4 \\ - & - & - & - & 10.2 & 2.0\end{array}$

$\begin{array}{cccccc}- & 2.8 & 4.2 & - & 2.8 & 2.0 \\ - & - & - & - & - & 0 \\ - & - & - & - & - & 0 \\ - & - & - & - & - & 0\end{array}$

$\begin{array}{cccccccccccc}- & 8.5 & 16.9 & 3.3 & 13.6 & 8.5 & - & 8.3 & 2.1 & - & 8.3 & 3.7 \\ - & 29.8 & 11.9 & 25.4 & 25.0 & 18.4 & 31.0 & 25.0 & 31.3 & - & 19.4 & 21.3 \\ - & - & 8.5 & 9.1 & - & 3.5 & - & - & 12.5 & 3.2 & - & 3.1 \\ 4.9 & 8.5 & - & - & - & 2.7 & - & - & 10.4 & 12.9 & - & 4.7\end{array}$




\section{Epidinium}

lunatus Van Hoven,1975

Opisthotrichum

janus Buisson, 1923

Number of species

$12 \quad 13$

$10 \quad 19$

9

14

9

8

10

22

${ }^{\mathrm{a}}$ Kofoid and MacLennan.

${ }^{\mathrm{b}}$ Species in bold print were previously identified in blesbok by van Hoven (1978). Two additional species reported by van Hoven were not found in the present material: Entodinium fyferi and Ostracodinium garstangi.

${ }^{c}$ Booyse and Dehority.

${ }^{\mathrm{d}}$ Cells were distorted and could not be identified below the genus level.

${ }^{\mathrm{e}}$ Ito, Arai,Tsutsumi and Imai. 
Although Entodinium parvum was only present in two animals in this study, Entodinium dubardi was found in 9 of the 10 blesbok. This is of interest based the similarity of these two species (Dehority, 1994).

A total of 27 species were observed in the present study.10 of which were previously reported from the blesbok by van Hoven (1978). These are shown in bold in Table 2. Thus the remaining 17 species constitute a new host record for blesbok. Adding the two additional species reported by van Hoven (1978) brings the total species for this host to 29 .

In summary, drinking the acid mine water reduced the concentration of rumen protozoa by about half. Although there was a shift in the generic percentages between groups, the same major species were present in both.

\section{References}

Abe, M., Shibui, T. \& Kumeno, F. (1973) Relation between diet and protozoal population in the rumen. British Journal of Nutrition, 29, 197-202.

Dehority, B.A. (1994) Rumen ciliate protozoa of the Blue Duiker (Cephalophus monticola) with observations on morphological variation lines within the species Entodinium dubardi. Journal of Eukaryotic Microbiology, 41, 103-111.

Dehority, B.A. (2005) Effect of pH on viability of Entodinium caudatum, Entodinium exiguum, Epidinium caudatum, and Ophryoscolex purkynjei in vitro. Journal of Eukaryotic Microbiology, 52, 339-342.

Dehority, B.A. \& Odenyo, A.A. (2003) Influence of diet on the rumen protozoal fauna of indigenous African wild ruminants. Journal of Eukaryotic Microbiology, 50, 220223.

Franzolin, R. \& Dehority, B.A. (1996) Effect of prolonged high-concentrate feeding on ruminal protozoa concentrations. Journal of Animal Science, 74, 2803-2809.

Latham, M.J., Sharpe, M.E. \& Sutton, J.D. (1971) The microbial flora of the rumen of cows fed hay and high cereal rations and its relationship to the rumen fermentation. Journal of Applied Bacteriology, 34, 425-434. 
Lyle, R.R., Johnson, R.R., Wilhite, J.V. \& Backus W.R. (1981) Ruminal characteristics in steers as affected by adaptation from forage to all -concentrate diets. Journal of Animal Science, 53, 1383-1390.

Mackie, R.I., Gilchrist, F.M.C., Robberts, A.M, Hannah, P.E., Schwartz HM. 1978. Microbiological and chemical changes in the rumen during the stepwise adaptation of sheep to high concentrate diets. Journal of Agricultural Science, 90, 241-254.

Nöthling, J.O., Du Toit, J.S. \& Myburgh, JG. (2014) Lead isotope ratios in bone ash of blesbok (Damaliscus pygargus phillipsi): A means of screening for the accumulation of contaminants from uraniferous rocks. Journal of Environmental Science and Health, Part A: Toxic/Hazardous Substances and Environmental Engineering, 49,1251-1257.

Towne, G.T., Nagaraja, G. \& Kemp, K.K. (1988) Ruminal ciliated protozoa in bison. Applied and Environmental Microbiology, 54, 2733-2736.

Vance, R.D., Preston, R.L., Klosterman, E.W. \& Cahill, V.R. (1972) Utilization of whole shelled and crimped corn grain with varying proportions of corn silage by growing finishing steers. Journal of Animal Science 35, 598-605.

Van Hoven, W. (1978) Development and seasonal changes in the rumen protozoan population in young blesbok (Damaliscus dorcas phillipsi Harper 1939). South African Journal of Wildlife Research 8, 127-130. 